\title{
Role of multidetector computed tomography (MDCT) in patients with ovarian masses
}

This article was published in the following Dove Press journal:

International Journal of Women's Health

4 April 201 I

Number of times this article has been viewed

\section{Fatima Mubarak Muhammad Shahbaz Alam \\ Waseem Akhtar \\ Saima Hafeez \\ Noureen Nizamuddin}

Radiology Department, Aga Khan University Hospital, Karachi, Pakistan
Correspondence: Fatima Mubarak Radiology Department, Aga Khan University Hospital, Stadium Road, PO Box 3500, Karachi, 74800 Pakistan Tel +92 2l 34862073

Email fatima.mubarak@aku.edu
Objective: To evaluate the diagnostic accuracy of multidetector 64-slice computed tomography (MDCT) in the diagnosis and differentiation of benign and malignant ovarian masses using histopathology and surgical findings as the gold standard.

Material and methods: This study was conducted in Aga Khan University Hospital, Karachi, Pakistan. Data was reviewed retrospectively from 1 November 2008 to 12 December 2009. One hundred patients found to have ovarian masses on CT scan were included in the study. CT scan was performed in all these patients after administration of oral and IV contrast. Ovarian masses were classified as benign and malignant on scan findings. Imaging findings were compared with histopathologic results and surgical findings. Sensitivity, specificity, positive predictive value (PPV), negative predictive value (NPV), and diagnostic accuracy of MDCT were calculated.

Results: MDCT was found to have $97 \%$ sensitivity, $91 \%$ specificity, and an accuracy of $96 \%$ in the differentiation of benign and malignant ovarian masses, while PPV and NPV were 97\% and $91 \%$, respectively.

Conclusion: MDCT imaging offers a safe, accurate and noninvasive modality to differentiate between benign and malignant ovarian masses.

Keywords: ovarian masses, surgery, MDCT

\section{Introduction}

Adnexal masses can be benign or malignant and the benign masses greatly outnumber malignant ones. ${ }^{1}$ Ovarian cancer is one of the most common gynecological malignancies and cause of death in the western world and the USA. It is also one of the most prevalent cancers in Pakistan. ${ }^{2,3}$ Precise characterization of an adnexal lesion is important as it dictates further management; hence, the role of radiology is very important. Until the last decade, exploratory laparotomy was used for the diagnosis and staging of adnexal masses, however, modern imaging techniques have demonstrated similar accuracy in the diagnosing and staging of ovarian carcinoma. Ultrasound is the first line modality to evaluate adnexal pathologies, however, most of the time it is unable to differentiate between benign and malignant lesions and the extent of disease in malignant cases. Sometimes when conventional ultrasound reveals complex morphology then other diagnostic tools can be used such as color Doppler and functional tumor vessel properties, serum CA 125 levels, nuclear magnetic resonance imaging, and in some cases laparoscopy. ${ }^{4} \mathrm{CT}$ is the investigation of choice in planning further management in patients believed to have metastatic disease. Multidetector computed tomography (MDCT) also allows comprehensive evaluation of primary tumour and the site of 
peritoneal metastasis and lymphadenopathy. On CT scan, masses can be characterized and features pertaining to benignity and malignancy can be observed. Local data regarding ovarian mass evaluation by MDCT are scarce. Therefore, the objective of this study was to evaluate the diagnostic accuracy of MDCT in our local population to differentiate between benign and malignant ovarian masses and to compare the findings with histopathologic results and surgery.

\section{Material and methods}

We retrospectively reviewed the preoperative MDCT findings of 100 ovarian tumors classified as either benign or malignant at subsequent surgical resection. Most patients had been referred for an asymptomatic adnexal mass. One had been referred because of pelvic pain, and two had been referred because of a previous ovarian cyst. The mean age of the patients was $50 \pm 17$ years with an age range from 19 to 82 years. Evaluators were blinded with surgical findings. We excluded patients with bilateral ovarian masses, concomitant carcinoma breast with metastatic disease, postoperative patients, those who were diagnosed as having malignant masses on ultrasound, and those in which origin from ovary was uncertain.

Patients were given oral nonionic contrast 2 hours before scanning. All scans were performed by MDCT on a 64 row CT scanner. The patients were scanned from the base of the lungs to the symphysis pubis after IV injection of $80-100 \mathrm{~mL}$ of nonionic contrast in portovenous phase with a scanning delay of 60-90s. Image slices of 10-mm-thickness were obtained followed by reconstruction in sagittal and coronal planes. MDCT images were reviewed by a consultant radiologist with experience in gynecological CT imaging. CT findings used to diagnose malignancy were: diameter greater than $4 \mathrm{~cm}$, cystic-solid mass, necrosis in a solid lesion, cystic lesion with thick, irregular walls or septa, and/or with papillary projections (Figure 1). Presence of ascites, peritoneal metastases, and lymphadenopathy were used to confirm malignancy. In addition, the presence of omental cake, peritoneal deposits, mesenteric deposits, and lymphadenopathy were also documented. Benign lesions have diameters less than $4 \mathrm{~cm}$ and well defined margins, without evidence of local or distant spread. Cystic lesions are unilocular, and have thin walls with minimal septations, and the absence of papillary projection. Statistical analysis was performed using SPSS (v.16; SPSS Inc; Chicago, IL). The sensitivity, specificity, positive predictive value (PPV), negative predictive value (NPV), and diagnostic accuracy were calculated.

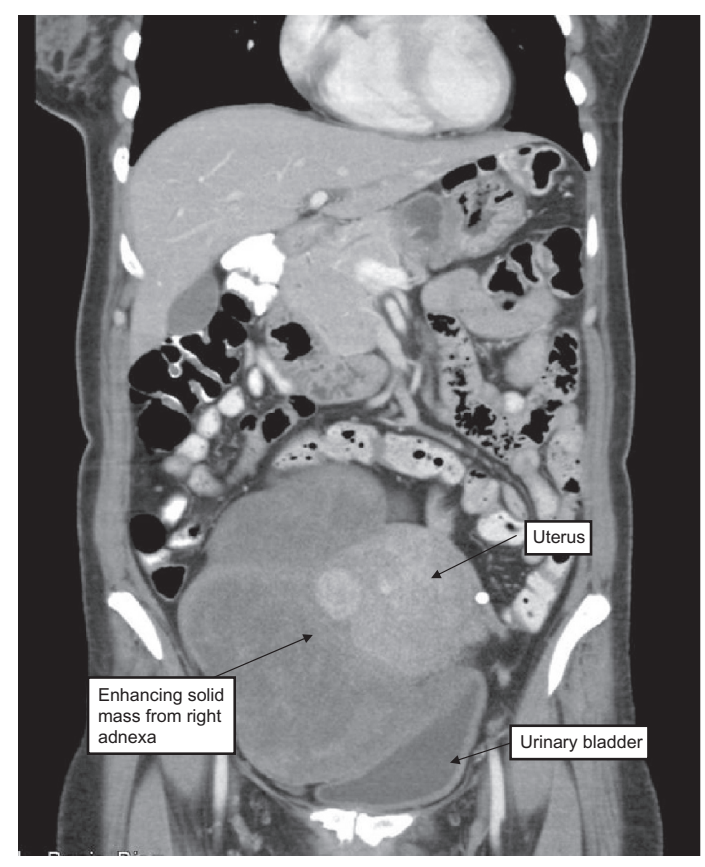

Figure I Fifty-year-old female presented with a palpable mass in the lower abdomen. Oral and IV contrast enhanced CT revealed $10 \mathrm{~cm}$ heterogeneously enhancing solid mass arising from right adnexa.

\section{Results}

Out of the 100 ovarian lesions, 76 were read by MDCT as malignant and 24 as benign lesions. On later histopathological findings, 76 of the 100 lesions had malignant lesions while 24 were benign. In the benign group, patients' ages ranged from 19-82 years (mean, 23.5 years). In the malignant group, patients' ages ranged from 48-72 years (mean, 60 years).

Malignant lesions included papillary carcinoma $(n=18)$, malignant mullerian tumor $(n=12)$, adenocarcinomas $(n=32)$, and endometrioid carcinomas $(\mathrm{n}=14)$. Benign lesions were simple ovarian cyst $(n=2)$, corpus luteal cyst $(n=2)$, benign cystadenoma $(n=4)$, dermoid $(n=2)$, teratomas $(n=2)$, and endometriomas $(n=12)$ (See Tables 1 and 2).

Table I Final diagnosis: benign lesions $n=24$

\begin{tabular}{ll}
\hline $\begin{array}{l}\text { Multidetector computed } \\
\text { tomography findings }\end{array}$ & $\begin{array}{l}\text { Histopathology/surgery } \\
\text { findings }\end{array}$ \\
\hline $\begin{array}{l}\text { Thin walled cyst, less than } 4 \mathrm{~cm} \text { in size } \\
\text { Thin walled cyst, less than } 4 \mathrm{~cm} \text { in size }\end{array}$ & $\begin{array}{l}\text { Simple ovarian cyst } \mathrm{n}=2 \\
\text { Corpus luteal cyst } \mathrm{n}=2\end{array}$ \\
$\begin{array}{l}\text { Thin walled cyst, less than } 4 \mathrm{~cm} \text { in size, } \\
\text { except in one case which was a solid lesion } \\
\text { of less than } 4 \mathrm{~cm} \text { in size with necrosis }\end{array}$ & Benign cystadenoma $\mathrm{n}=4$ \\
$\begin{array}{l}\text { Solid lesion, thick wall, calcifications } \\
\text { Thin walled cyst of less than } 4 \mathrm{~cm}\end{array}$ & Dermoid cyst $\mathrm{n}=2$ \\
$\begin{array}{l}\text { in size, few areas of hemorrhage } \\
\text { Solid well defined lesion, fat density, } \\
\text { except one which had central necrosis }\end{array}$ & Teratoma $\mathrm{n}=2$ \\
and no fat density & \\
\hline
\end{tabular}


Table 2 Final diagnosis: malignant lesions $\mathrm{n}=76$

\begin{tabular}{|c|c|}
\hline $\begin{array}{l}\text { Multidetector computed } \\
\text { tomography findings }\end{array}$ & $\begin{array}{l}\text { Histopathology/surgery } \\
\text { findings }\end{array}$ \\
\hline $\begin{array}{l}\text { Thick walled, large solid cum } \\
\text { cystic mass, ascites, lymphnodes }\end{array}$ & Papillary carcinoma $n=18$ \\
\hline $\begin{array}{l}\text { Thick walled, large masses with } \\
\text { central necrosis }\end{array}$ & Malignant mullerian $n=12$ \\
\hline $\begin{array}{l}\text { Large multiseptated, solid cum cystic, } \\
\text { ascites except one which was a large } \\
\text { cyst with thin internal septations }\end{array}$ & Adenocarcinoma $n=32$ \\
\hline $\begin{array}{l}\text { Large solid masses, lymph nodes, } \\
\text { omental thickening except one } \\
\text { which was less than } 4 \mathrm{~cm} \text { and had } \\
\text { well defined thin walls }\end{array}$ & Endometriod carcinoma $\mathrm{n}=14$ \\
\hline
\end{tabular}

There were two false positive cases: one on imaging appeared as a solid lesion with necrosis and an adherent fallopian tube; and the other one had an adjacent endometrioma deposit on the broad ligament which we mistakenly identified as a solid component. Both cases also had ascites as an ancillary finding.

Similarly there were two false negative results: one which we labeled as benign on the basis of its small size, $<4 \mathrm{~cm}$, and well defined wall, which was an endometrioid carcinoma; and the other which we identified as a large simple cyst with thin septations was found to be a mucinous cyst adenocarcinoma via histopathology.

Thus, there were 74 true positives, 2 false positives, 22 true negative, and 2 false negative results reported on MDCT based assessment. Overall, MDCT was found to have 97.3\% sensitivity, $91.6 \%$ specificity, and an accuracy of $96 \%$ in the differentiation of benign and malignant ovarian masses, while PPV and NPV were $97.3 \%$ and $91.6 \%$, respectively.

\section{Discussion}

In day-to-day practice, we come across many cases of adnexal masses. Some of these turn out to be benign, some borderline, and some malignant. When an ovarian mass is detected, there are two major issues: to determine whether it is benign or malignant, and then if it is malignant, to look for the extent of disease. ${ }^{5,6}$ If the nature of the mass is adequately determined on the image, then it saves the patient unnecessary surgery and expense. Similarly if staging is accurately done on imaging, again it becomes cost-effective and it helps in further planning. ${ }^{7,8}$

However, we understand that surgery has a role in definite diagnosis and the further characterization of masses. Sometimes $\mathrm{CT}$ underestimates staging and pelvic examination by a gynecologist and serum CA-125 are of limited value in the diagnosis of pelvic masses and their sensitivity is often below $50 \% .{ }^{8}$ The sensitivity of morphologic analysis with ultrasound in predicting malignancy in ovarian tumors has been shown to be $85 \%-97 \%$, whereas its specificity ranges from $56 \%-95 \%{ }^{9-11}$

Our results are comparable to previously published international literature (Table 3). ${ }^{12-14} \mathrm{~A}$ meta-analysis conducted by Kinkel et al described that $\mathrm{CT}$ shows sensitivity and specificity of $81 \%$ and $87 \%$ respectively when used for indeterminate masses seen on ultrasound. ${ }^{12}$ Similarly, Liu et al reported that PET/CT scanner shows a sensitivity of $87 \%$ and specificity of $100 \%$ for differentiating benign from malignant ovarian cancers. ${ }^{14}$ Tsili et al also described in their study that MDCT can categorize adnexal masses into benign and malignant in up to $93 \%$ and $89 \%$ of the cases. ${ }^{13}$ Our study reported a sensitivity and specificity of $97 \%$ and $91 \%$, respectively.

$\mathrm{CT}$ appearances of ovarian masses vary widely and accurate histologic characterization is not always possible. Although tumor markers like CA-125, AFP, and HCG are indicative of ovarian cancer and germ cell tumors respectively, careful consideration inspite of the components of the masses and evidence of malignant spread are useful from a management aspect. ${ }^{15,16}$

Certain radiologic findings predominate for each type of tumor; knowledge of these key features of ovarian tumors may allow a specific diagnosis or substantial narrowing of differential diagnosis. ${ }^{17-19}$ The image appearance of ovarian tumors ranges from cystic to solid masses. Although tumors have similar clinical and radiological findings, predominant or specific key features are present in each type of ovarian tumor. $^{20-22}$

Our study shows high accuracy (96\%), however, there were two false positive and two false negative results. Lesions characterized as benign have imaging characteristics similar to benign lesions, ie, less than $4 \mathrm{~cm}$ in size, smooth walls without thick septations, making evaluation of these tumors difficult. Similarly, regarding false positive results, these lesions have characteristics of malignant lesions, ie, solid lesions with necrosis, infiltration to adjacent organs and

Table 3 Sensitivity and specificity of multidetector computed tomography in differentiating benign from malignant adnexal masses

\begin{tabular}{|c|c|c|}
\hline Author & Sensitivity (\%) & Specificity (\%) \\
\hline Kinkel et al' ${ }^{12}$ & 81 & 87 \\
\hline Tsili et al ${ }^{13}$ & 90 & 88 \\
\hline Liu et $\mathrm{al}^{14}$ & 87 & 100 \\
\hline Mubarak et $\mathrm{al}^{\mathrm{a}}$ & 97 & 91 \\
\hline
\end{tabular}

Note: athe present study. 
the presence of ascites. These features make it difficult to recognize on images, resulting in false positive and negative results. Other possibilities include interpretation error or not using reformatted images properly.

Our study has a few limitations besides the small number of benign cases included in the sample. Only those patients who were referred to MDCT scan were included, which introduces bias. No interobserver agreement for MDCT images evaluation was calculated.

\section{Conclusion}

MDCT is an excellent noninvasive modality to differentiate adnexal masses from benign and malignant causes, and the CT findings used to diagnose malignancy were: diameter greater than $4 \mathrm{~cm}$, cystic-solid mass, necrosis in a solid lesion, cystic lesion with thick, irregular walls or septa, and/or with papillary projections. The presence of ascites, peritoneal metastases, and lymphadenopathy was also used to confirm malignancy.

\section{Disclosure}

The authors report no conflicts of interest in this work.

\section{References}

1. Jeong YY, Outwater EK, Kang HK. Imaging evaluation of ovarian masses. Radiographics. 2000;20:1445-1470.

2. Aziz Z, Sana S, Saeed S, Akram M. Institution based tumor registry from Punjab: five year data based analysis. J Pak Med Assoc. 2003;53: 350-353.

3. Tanwani AK. Prevalence and patterns of ovarian lesions. Ann Pak Inst Med Sci. 2005;1:211-214.

4. Pérez-López FR, Chedraui P, Troyano-Luque JM. Peri- and postmenopausal incidental adnexal masses and the risk of sporadic ovarian malignancy: new insights and clinical management. Gynecol Endocrinol. 2010;26:631-643.

5. Woodward PJ, Hosseinzadeh K, Saenger JS. Radiologic staging of ovarian carcinoma with pathologic correlation. Radiographics. 2004;24: 225-246.

6. Iyer VR, Lee SI. MRI, CT, and PET/CT for ovarian cancer detection and adnexal lesion characterization. AJR. 2010;194:311-321.
7. Lalwani N, Shanbhogue AKP, Vikram R, Nagar A, Jagirdar J, Prasad SR. Current update on borderline ovarian neoplasms. AJR. 2010;194: 330-336.

8. Prakash P, Cronin CG, Blake MA. Role of PET/CT in ovarian cancer. AJR. 2010;194:W464-W470.

9. Tempany CM, Zou KH, Silverman SG, Brown DL, Kurtz AB, McNeil BJ. Staging of advanced ovarian cancer: comparison of imaging modalities-report from the Radiological Diagnostic Oncology Group. Radiology. 2000;215:761-767.

10. Baert AL, Forstner R. Encyclopedia of diagnostic imaging: carcinoma ovarium. Vol 1. New York: Springer; 2008:259.

11. Nam E, Kim Y, Kim J, et al. Kim. Diagnosis and staging of ovarian cancer: comparative values of PET/CT, Doppler US, CT, and MRI correlated with histopathologic analysis. J Clin Oncol. 2008;26(15S): 5567.

12. Kinkel K, Lu Y, Mehdizade A, Pelte MF, Hricak H. Indeterminate ovarian mass at ultrasound: incremental value of second imaging test for characterization-meta analysis and Bayesian analysis. Radiology. 2005;236:85-94.

13. Tsili AC, Tsampoulas C, Charisiadi A, et al. Adnexal masses: accuracy of detection and differentiation with multidetector computed tomography. Gynecol Oncol. 2008;110:22-31.

14. Liu Y. Benign ovarian and endometrial uptake on FDG PET-CT: patterns and pitfalls. Ann Nucl Med. 2009;23:107-112.

15. Sengupta PS, Shanks JH, Buckley CH. Requirement for expert histopathological assessment of ovarian cancer and borderline tumors. Br J Cancer. 2000;82:760-762.

16. Kurtz AB, Tsimikas JV, Tempany CMC, et al. Diagnosis and staging of ovarian cancer: comparative values of Doppler and conventional US, CT, and MR imaging correlated with surgery and histopathologic analysis - report of the Radiology Diagnostic Oncology Group. Radiology. 1999;212:19-27.

17. Spencer JA. A multidisciplinary approach to ovarian cancer at diagnosis. Br J Radiol. 2005;78:S94-S102.

18. Imaoka I, Wada A, Kaji Y, et al. Developing an MR imaging strategy for diagnosis of ovarian masses. Radiographics. 2006;26:1431-1448.

19. Tamai K, Koyama T, Saga T, et al. MR features of physiologic and benign conditions of the ovary. Eur Radiol. 2006;16:2700-2711.

20. Brown DL, Zou KH, Tempany CMC, et al. Primary versus secondary ovarian malignancy: imaging findings of adnexal masses in the Radiology Diagnostic Oncology Group Study. Radiology. 2001;219: 213-218.

21. Andersen ES, Knudsen A, Rix P, Johansen B. Risk of malignancy index in the preoperative evaluation of patients with adnexal masses. Gynecol Oncol. 2003;90:109-112.

22. Altekruse SF, Kosary CL, Krapcho M, et al. SEER Cancer Statistics Review, 1975-2007, National Cancer Institute. Bethesda, MD. Available from: http://seer.cancer.gov/csr/1975_2007/. Accessed February 15, 2011.
International Journal of Women's Health

\section{Publish your work in this journal}

The International Journal of Women's Health is an international, peerreviewed open-access journal publishing original research, reports, reviews and commentaries on all aspects of women's healthcare including gynecology, obstetrics, and breast cancer. Subject areas include: Chronic conditions (migraine headaches, arthritis, osteoporosis);

\section{Dovepress}

Endocrine and autoimmune syndromes; Sexual and reproductive health; Psychological and psychosocial conditions. The manuscript management system is completely online and includes a very quick and fair peer-review system. Visit http://www.dovepress.com/ testimonials.php to read real quotes from published authors. 